\title{
Efeito do ômega 3 e da vitamina B12 no espermograma, na histomorfometria dos órgãos reprodutivos e nas temperaturas do corpo com termografia infravermelha em ratos Wistar
}

[Effect of Omega 3 and Vitamin B12 on the spermogram, histomorphometry of the reproductive organs and body temperatures with infrared thermography in Wistar rats]

\author{
L.M.M. Yamada ${ }^{1}$, C.D. Souza ${ }^{1}$, I.T. Branco ${ }^{1}$, I.B. Andrade ${ }^{1}$, F.L.G.B. Deak ${ }^{1}$, G.P. Bastos ${ }^{1}$, \\ J.G. Silva ${ }^{1}$, J.V.R. Amoris ${ }^{1}$, L.Y. Yamada ${ }^{1}$, P.F.I. Goiozo ${ }^{1}$, C.P. Cremasco ${ }^{2}$, \\ L.R.A. Gabriel Filho ${ }^{2}$, M.G.M. Chacur ${ }^{1}$ \\ ${ }^{1}$ Universidade do Oeste Paulista - Presidente Prudente, SP \\ ${ }^{2}$ Universidade Estadual Paulista (UNESP), Faculdade de Ciências e Engenharia, Tupã
}

\begin{abstract}
RESUMO
Objetivou-se estudar o efeito do ômega 3 e da vitamina B12 no espermograma, na histomorfometria dos órgãos reprodutivos e na temperaturas do corpo com termografia infravermelha em ratos Wistar. Utilizaram-se 16 ratos, em quatro grupos $(n=4)$, que receberam injeções diárias por 30 dias, sendo: grupo controle - solução salina; grupo ômega 3 - óleo de peixe $1 \mathrm{~g} / \mathrm{kg}$; grupo B12 - vitamina B12 $3 \mu \mathrm{g}$; e grupo

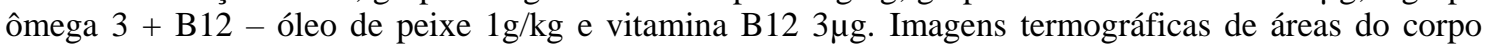
foram obtidas. No $30^{\circ}$ dia, os ratos foram sacrificados e realizaram-se as análises de morfologia espermática e histomorfometria. Os dados foram submetidos à análise de variância e ao teste de Tukey a $5 \%$. A temperatura da superfície do escroto foi superior no grupo B12 (P<0,05). Não houve diferenças entre grupos $(\mathrm{P}>0,05)$ para temperaturas do globo ocular. Houve correlação entre temperatura da superfície do escroto e porcentagem de gota citoplasmática distal $(\mathrm{P}=0,678)$. A elevação da temperatura do escroto resulta no aumento da porcentagem de gotas citoplasmáticas distais. A temperatura do globo ocular não sofre influência significativa do ômega 3 e da vitamina B12. O ômega 3 reduz o epitélio seminífero, e a vitamina B12 minimiza esse efeito.
\end{abstract}

Palavras-chave: óleo de peixe, cianocobalamina, aparelho reprodutor, termograma

\begin{abstract}
The objective of this study was to study the effect of Omega 3 and vitamin B12 on spermogram, histomorphometry of reproductive organs and body temperature with infrared thermography in Wistar rats. Sixteen rats were used in four groups $(n=4)$ who received daily injections for 30 days. Control Group - saline solution; Group Omega 3 - fish oil 1g/kg; Group B12 - vitamin B12 $3 \mu \mathrm{g}$ and Group

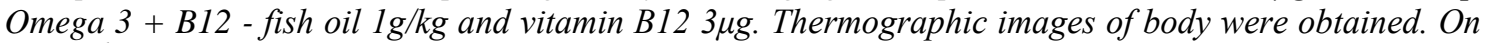
the $30^{\text {th }}$ day the rats were sacrificed and analyzes of sperm morphology and histomorphometry were performed. Data were submitted to analysis of variance and Tukey's test at 5\%. The surface temperature of the scrotum was higher in group B12 $(P<0.05)$. There were no differences between groups $(P>0.05)$ for eyeball temperatures. There was a correlation between scrotal temperature and distal cytoplasmic droplet $(P=0.678)$. Elevation of scrotum temperature results in an increase in the percentage of distal cytoplasmic droplets. The temperature of the eyeball is not significantly influenced by Omega 3 and vitamin B12. Omega 3 reduces the seminiferous epithelium and vitamin B12 minimizes this effect.
\end{abstract}

Keywords: fish oil, cyanocobalamin, reproductive system, thermogram

Recebido em 13 de junho de 2017

Aceito em 16 de dezembro de 2017

E-mail: luciyanutri@yahoo.com.br 


\section{INTRODUÇÃO}

Métodos alternativos e inovadores para mitigar o estresse em animais de biotério são estudados para atender às normativas inerentes ao bemestar animal. Um dos métodos usados e recomendados para mensurar a temperatura do corpo em animais é a termografia digital com infravermelho. É um exame de imagem de alta acurácia, que reduz o estresse provocado por métodos invasivos. Esse método processa informações e fornece imagens térmicas bidimensionais, facilitando comparações entre as áreas examinadas do corpo (Vogel et al., 2016).

A temperatura corporal é um parâmetro fisiológico importante para monitorar a saúde e o equilíbrio da termorregulação (Adamkovicova et al., 2014). A temperatura do escroto influencia na produção de espermatozoides pelas células germinativas dos túbulos seminíferos. A dieta alimentar é um dos fatores que influenciam na temperatura do corpo e na produção de espermatozoides (Mendeluk et al., 2015; Griswold, 2016). Alimentação inadequada, deficiências nutricionais e baixa ingestão de antioxidantes causam desequilíbrios na produção de espécies reativas de oxigênio (ROS) (Mendeluk et al. 2015). A qualidade dos espermatozoides está relacionada ao estresse oxidativo, que reduz os níveis de ATP intracelular, causa peroxidação lipídica no plasmalema e tem impacto negativo na fertilidade (Giahi et al., 2016).

A ingestão de antioxidantes reduz o estresse oxidativo, como o óleo de peixe, que contêm ômega 3, uma importante fonte de ácido eicosapentanoico (EPA, C20: 5 n-3) e ácido docosa-hexaenoico (DHA, C22: 6 n-3) (Risso et al., 2016). Na incapacidade de sintetizá-los, há a necessidade de ingestão dietética para suprir funções orgânicas; além disso, eles possuem efeito anti-inflamatório e antioxidante (Kemse et al., 2014). Teores elevados de DHA melhoram a qualidade do sêmen e foram associados com melhor morfologia devido à redução da porcentagem de gametas portadores de defeitos de cabeça (Mendeluk et al., 2015). A vitamina B12 é um micronutriente essencial, obtido na ingestão dietética (Hannibal et al., 2016), que inibe espécies reativas de oxigênio (ROS) produzidas por meio do estresse oxidativo no sêmen. Essa vitamina é ativa durante a divisão celular e a síntese de DNA, e a deficiência eleva a porcentagem de patologias espermáticas (Hamedani et al., 2013).

O presente estudo se justifica por mensurar as temperaturas da superfície de áreas do corpo, com o uso de uma câmera termográfica, de maneira não invasiva e com acurácia comprovada, o que colabora para o bem-estar animal. Objetivou-se estudar o efeito do ômega 3 e da vitamina B12 no espermograma, na histomorfometria dos órgãos reprodutivos e nas temperaturas do corpo com termografia infravermelha em ratos Wistar.

\section{MATERIAL E MÉTODOS}

O experimento foi aprovado pela Comissão de Ética e Uso de Animais da Universidade do Oeste Paulista, sob o protocolo 2995. Foram utilizados ratos Wistar adultos, machos $(n=16)$, com peso corpóreo médio de $285,0 \pm 11,8 \mathrm{~g}$, mantidos 30 dias em ciclo de claro e escuro de 12/12 horas, divididos randomicamente em quatro grupos ( $\mathrm{n}=4 /$ grupo). Cada grupo era colocado em uma caixa com água e ração (Padrão MP77®, Moinho Primor S.A., Brasil) ad libitum. O tratamento era injetado diariamente (entre oito e 10 horas), por 30 dias, via subcutânea, nos quatro grupos: controle (GC) solução salina estéril a $0,9 \%$; ômega 3 - óleo de peixe (Ômega 3, Equaliv, Brasil) 1g/kg (Hirabara et al., 2012); vitamina B12 (GB12) - vitamina

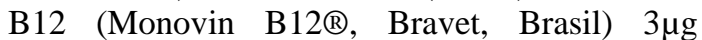
(Oliveira, 2013); e ômega 3 + vitamina B12 (Gn3B12) - óleo de peixe $(1 \mathrm{~g} / \mathrm{kg})$ e vitamina $\mathrm{B} 12(3 \mu \mathrm{g})$.

Foram realizadas termografias digitais por infravermelho, diariamente, durante 30 dias, entre oito e 10 horas, com câmera termográfica (E-40®, Flir, Suécia). Para mitigar o estresse, antes dos procedimentos, os animais foram retirados da caixa, e as imagens capturadas com o foco emissor a $30 \mathrm{~cm}$ do escroto, da região perianal, do ísquio, do prepúcio, do focinho, do globo ocular e da região entre olhos. As imagens foram processadas pelo programa Flir Tools 2.1® (Flir Systems, EUA), com o uso de polígonos para mensurar temperaturas das áreas estudadas.

No dia 30 do experimento, todos os ratos dos quatro grupos foram sacrificados por 
exsanguinação, via punção cardíaca, sob anestesia com tiobarbitúrico (Thiopentax ${ }^{\circledR}$, Cristália, Brasil), com dose de $80 \mathrm{mg} / \mathrm{kg}$ de peso corpóreo via intraperitoneal. Após a morte, foram coletados testículos, epidídimos e vesículas seminais, os quais foram pesados em balança de precisão. Seguiu-se a separação de fragmentos desses órgãos, que foram fixados imediatamente em solução de formalina tamponada a $10 \%$ por 24 horas. Logo depois, esses fragmentos foram colocados em álcool $70^{\circ} \mathrm{GL}$ até o processamento histológico. Após fixação, esses tecidos foram processados e corados com hematoxilina e eosina (HE) para análises histológica e morfométrica em cortes de $5 \mu \mathrm{m}$ de espessura. Para as análises morfométricas, utilizou-se programa computacional (Software Motic Images Plus ${ }^{\circledR}$ version 2.0) (Motic China Group CO., LTD, 2010), por meio do qual foram realizadas mensurações de 10 campos dos componentes teciduais dos testículos, dos epidídimos e das vesículas seminais. Nos testículos, determinou-se a área tubular, a área do lúmen tubular, a área de células de Leydig e a área de estroma, enquanto a área do epitélio germinativo foi determinada subtraindo-se a área do lúmen tubular da área tubular. Nos epidídimos, mensurou-se a área tubular, a área de estroma e a área da massa espermática. Nas vesículas seminais, obteve-se a área do epitélio tubular subtraindo-se a área do lúmen da área tubular.

Após coletar e dissecar os epidídimos, realizouse uma secção em sua porção caudal com o auxílio do bisturi e depositou-se o conteúdo contendo espermatozoides na lâmina. Em seguida, acrescentaram-se cinco gotas de solução salina e, após um minuto, realizou-se o esfregaço. Posteriormente, coraram-se as lâminas pelo método panótico rápido, sendo 10 imersões em cada uma das três soluções. Realizou-se a leitura da morfologia espermática em microscópio óptico (1000x), por meio da qual foram contados 200 espermatozoides e consideraram-se os seguintes defeitos: patologia de cabeça, patologia de cauda, gota citoplasmástica distal e gota citoplasmástica proximal (Filler, 1993).

Para análise estatística, foi realizada uma análise de variância com significância $\mathrm{P} \leq 0,05 \mathrm{e}$, nas amostras não paramétricas, utilizou-se o teste de Tukey, com significância $\mathrm{P} \leq 0,05$, por meio do software Minitab ${ }^{\circledR} 16.0$ (Minitab, 2010).

\section{RESULTADOS}

A temperatura do escroto foi superior no GB12 $(\mathrm{P} \leq 0,05)$ em relação aos demais grupos. No Gn3, encontrou-se temperatura maior comparado ao GC. No Gn3B12, a temperatura ficou semelhante ao GC e ao grupo ômega 3. Nas imagens do prepúcio, a temperatura maior foi encontrada no GB12, mas estatisticamente este não diferiu dos grupos ômega 3 e ômega 3 + B12; porém foi superior $(\mathrm{P} \leq 0,05)$ à do GC. A temperatura do focinho foi maior $(\mathrm{P} \leq 0,05)$ nos animais tratados com Gn3 em comparação ao GC; no entanto, sem diferença estatística em relação aos demais grupos. Avaliações realizadas nas regiões perianal, ísquio, globo ocular e entre olhos não apresentaram diferenças significativas entre os grupos (Tab. 1).

Nas análises do peso dos órgãos do aparelho reprodutor dos ratos Wistar machos, não houve diferença $(\mathrm{P} \leq 0,05)$ entre tratamentos (Tab. 2), sem evidenciar alteração macroscópica.

Tabela 1. Médias e desvios-padrão de temperatura média $\left({ }^{\circ} \mathrm{C}\right)$ de áreas do corpo de ratos Wistar adultos, tratados com ômega 3 e ou vitamina B12, por via subcutânea, durante 30 dias

\begin{tabular}{lcccccccc}
\hline \multicolumn{1}{c}{ Área do corpo } & \multicolumn{1}{c}{ Controle } & \multicolumn{3}{c}{ Ômega 3} & & Vitamina B12 & \multicolumn{2}{c}{$\begin{array}{c}\text { Omega } 3+ \\
\text { vitamina B12 }\end{array}$} \\
\hline Escroto & $27,2 \pm 1,8$ & $\mathrm{c}$ & $27,8 \pm 2,2$ & $\mathrm{~b}$ & $28,5 \pm 2,2$ & $\mathrm{a}$ & $27,8 \pm 1,8$ & $\mathrm{bc}$ \\
Perianal & $30,8 \pm 1,5$ & $\mathrm{a}$ & $30,8 \pm 1,2$ & $\mathrm{a}$ & $30,8 \pm 1,3$ & $\mathrm{a}$ & $30,2 \pm 1,2$ & $\mathrm{a}$ \\
Ísquio & $28,7 \pm 1,8$ & $\mathrm{a}$ & $29,0 \pm 1,8$ & $\mathrm{a}$ & $29,1 \pm 1,6$ & $\mathrm{a}$ & $28,7 \pm 1,4$ & $\mathrm{a}$ \\
Prepúcio & $29,4 \pm 1,7$ & $\mathrm{~b}$ & $29,8 \pm 2,0$ & $\mathrm{ab}$ & $30,3 \pm 1,6$ & $\mathrm{a}$ & $29,7 \pm 1,5$ & $\mathrm{ab}$ \\
Focinho & $24,6 \pm 0,3$ & $\mathrm{~b}$ & $26,5 \pm 1,0$ & $\mathrm{a}$ & $26,2 \pm 1,1$ & $\mathrm{ab}$ & $26,6 \pm 1,3$ & $\mathrm{ab}$ \\
Globo ocular & $33,0 \pm 0,9$ & $\mathrm{a}$ & $33,8 \pm 0,6$ & $\mathrm{a}$ & $33,3 \pm 1,0$ & $\mathrm{a}$ & $35,0 \pm 0,8$ & $\mathrm{a}$ \\
Entre olhos & $28,7 \pm 0,5$ & $\mathrm{a}$ & $29,8 \pm 0,7$ & $\mathrm{a}$ & $29,0 \pm 0,9$ & $\mathrm{a}$ & $30,4 \pm 0,7$ & $\mathrm{a}$ \\
\hline
\end{tabular}

Médias seguidas por letras minúsculas diferentes nas linhas $(\mathrm{P} \leq 0,05)$ pelo teste de Tukey. Letra "a" representa as temperaturas maiores, "b" as intermediárias e "c" as menores. 
Tabela 2. Médias e desvios-padrão do peso relativo em gramas (g) de órgãos de ratos Wistar adultos, tratados com ômega 3 e ou vitamina B12, por via subcutânea, durante 30 dias

\begin{tabular}{lcccc}
\multicolumn{1}{c}{ Órgãos } & Controle & Ômega 3 & Vitamina B12 & Ômega 3 + vitamina B12 \\
\hline Testículo & $2,7 \pm 0,3$ & $2,9 \pm 0,1$ & $2,9 \pm 0,0$ & $2,4 \pm 0,1$ \\
Epidídimo & $2,6 \pm 1,0$ & $2,7 \pm 0,5$ & $1,5 \pm 0,0$ & $1,5 \pm 0,1$ \\
Vesícula seminal & $8,6 \pm 2,5$ & $7,5 \pm 3,8$ & $12,5 \pm 11,9$ & $5,8 \pm 4,8$ \\
\hline
\end{tabular}

A histologia do testículo, do epidídimo e da vesícula seminal está ilustrada na Fig. 1.

Nas análises morfométricas de testículo (Tab. 3), observou-se que, no grupo ômega 3 , houve aumento $(\mathrm{P} \leq 0,05)$ na porcentagem de estroma e redução $(\mathrm{P} \leq 0,05)$ na porcentagem de epitélio seminífero, comparado ao grupo controle e ao grupo vitamina $\mathrm{B} 12$, os quais não diferiram $(\mathrm{P} \geq 0,05)$ entre si. $\mathrm{O}$ grupo ômega $3+$ vitamina B12 foi estatisticamente semelhante a todos os grupos. O epidídimo e a vesícula seminal não apresentaram diferenças estatísticas entre os grupos. Encontrou-se, no grupo controle, $80,8 \pm 6,9 \%$ de estroma e $19,2 \pm 6,9 \%$ de epitélio.
Para a morfologia espermática (Tab. 4), o grupo B12 apresentou uma porcentagem de espermatozoides normais superior $(\mathrm{P} \leq 0,05)$ comparado aos demais grupos. Porcentagem menor $(\mathrm{P} \leq 0,05)$ de espermatozoides com patologia de cabeça e porcentagem maior $(\mathrm{P} \leq 0,05)$ de gota distal foram observadas no GB12. A ocorrência de gametas com patologia de cauda e gota proximal não apresentou diferenças entre os grupos.

Observa-se que a gota citoplasmática distal está altamente correlacionada, de forma positiva, com a temperatura do escroto mensurada com termografia infravermelha. Nas demais correlações, não houve diferenças significativas $(\mathrm{P}>0,05)($ Tab. 5).

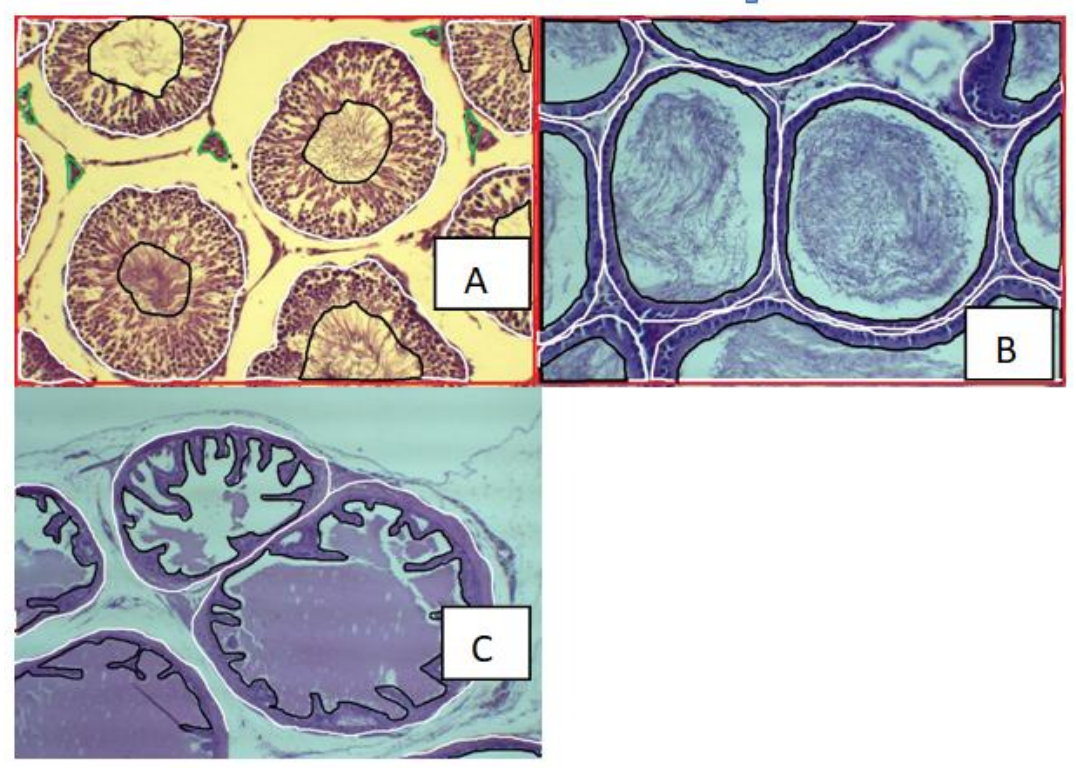

Figura 1. Análises morfométricas de testículos, epidídimos e vesícula seminal de ratos Wistar, adultos, tratados com ômega 3 e ou vitamina B12, por via subcutânea, durante 30 dias. (A) Histomorfometria testicular: linha vermelha = área total; linha preta = área de luz tubular; linha branca = área tubular; linha verde = área de células de Leydig; área de epitélio germinativo = área tubular - área de luz tubular; área de estroma = área total $-(\Sigma$ área tubular $+\Sigma$ área de células de Leydig). HE 400x. (B) Histomorfometria epididimária: linha vermelha = área total; linha preta = área de luz tubular; linha branca = área tubular; área de epitélio = área tubular - área de luz tubular; área de estroma = área total $-\Sigma$ área tubular. HE 400x. (C) Histomorfometria vesícula seminal: linha preta = área do lúmen; linha branca = área tubular; área do epitélio tubular = área tubular - área do lúmen. HE 400x. 
Efeito do ômega 3...

Tabela 3. Médias e desvios-padrão para o epitélio testicular (\%) e o estroma testicular (\%) de ratos Wistar adultos, tratados com ômega 3 e ou vitamina B12, por via subcutânea, durante 30 dias

\begin{tabular}{|c|c|c|c|c|c|c|}
\hline Testículo & Controle & & Ômega 3 & & Vitamina B12 & $\begin{array}{c}\text { Ômega } 3+ \\
\text { vitamina B12 }\end{array}$ \\
\hline estroma $(\%)$ & $26,08 \pm 11,55$ & b & $37,38 \pm 13,03$ & $\mathrm{a}$ & $22,01 \pm 13,62$ & $30,59 \pm 11,38$ \\
\hline epitélio (\%) & $73,92 \pm 11,55$ & $\mathrm{a}$ & $62,62 \pm 13,03$ & $\mathrm{~b}$ & $77,99 \pm 13,62$ & $69,41 \pm 11,38$ \\
\hline
\end{tabular}

Médias seguidas por letras minúsculas diferentes nas linhas $(\mathrm{P} \leq 0,05)$ pelo teste de Tukey. Letra "a" representa as temperaturas maiores, e "b" as menores.

Tabela 4. Médias e desvios-padrão para porcentagens de defeitos espermáticos de ratos Wistar adultos, tratados com ômega 3 e ou vitamina B12, por via subcutânea, durante 30 dias

\begin{tabular}{|c|c|c|c|c|c|c|c|c|}
\hline Defeitos espermáticos & \multicolumn{2}{|c|}{ Controle } & \multicolumn{2}{|c|}{ Ômega 3} & \multicolumn{2}{|c|}{ Vitamina B12 } & \multicolumn{2}{|c|}{$\begin{array}{c}\text { Ômega } 3+ \\
\text { vitamina B12 }\end{array}$} \\
\hline Normais & $75,8 \pm 9,3$ & $\mathrm{~b}$ & $70,8 \pm 13,8$ & $\mathrm{~b}$ & $79,5 \pm 4,2$ & $\mathrm{a}$ & $71,0 \pm 20,0$ & $\mathrm{~b}$ \\
\hline Patologia de cabeça & $20,8 \pm 7,6$ & $\mathrm{a}$ & $23,0 \pm 14,4$ & $\mathrm{a}$ & $8,5 \pm 3,7$ & $b$ & $28,0 \pm 16,4$ & $\mathrm{a}$ \\
\hline Patologia de cauda & $5,8 \pm 0,9$ & $\mathrm{a}$ & $7,5 \pm 4,1$ & $\mathrm{a}$ & $5,0 \pm 4,5$ & a & $6,0 \pm 1,7$ & $\mathrm{a}$ \\
\hline Gota distal & $1,8 \pm 1,5$ & b & $0,5 \pm 0,6$ & b & $9,5 \pm 3,1$ & $\mathrm{a}$ & $2,3 \pm 1,5$ & $\mathrm{~b}$ \\
\hline Gota proximal & $0,0 \pm 0,0$ & $\mathrm{a}$ & $0,5 \pm 0,3$ & $\mathrm{a}$ & $0,0 \pm 0,0$ & $\mathrm{a}$ & $0,0 \pm 0,0$ & $\mathrm{a}$ \\
\hline
\end{tabular}

Médias seguidas por letras minúsculas diferentes nas linhas $(\mathrm{P} \leq 0,05)$ pelo teste de Tukey.

Tabela 5. Correlações entre temperatura do escroto com termografia infravermelha e morfologia espermática de ratos Wistar adultos, tratados com ômega 3 e ou vitamina B12, por via subcutânea, durante 30 dias

\begin{tabular}{cccccccccccc} 
& Normais & $P$ & $\begin{array}{c}\text { Patologia } \\
\text { de cabeça }\end{array}$ & $P$ & $\begin{array}{c}\text { Patologia } \\
\text { de } \\
\text { cauda }\end{array}$ & $P$ & $\begin{array}{c}\text { Gota } \\
\text { distal }\end{array}$ & $P$ & $\begin{array}{c}\text { Total de } \\
\text { defeitos }\end{array}$ & $P$ \\
\hline $\begin{array}{c}\text { T }\left({ }^{\circ} \mathrm{C}\right) \\
\text { escroto }\end{array}$ & 0,053 & 0,856 & $-0,347$ & 0,224 & 0,010 & 0,972 & $0,678^{*}$ & 0,008 & $-0,133$ & 0,651 \\
\hline
\end{tabular}

\section{DISCUSSÃO}

Uma imagem termográfica de infravermelho, ou termograma, mostra, de forma clara e precisa, elevação local ou queda da temperatura, refletindo o aporte de sangue de determinada área, que está diretamente relacionada a uma série de processos fisiológicos ou patológicos (Usamentiaga et al., 2014).

Tanto a temperatura do globo ocular como a da orelha, usando-se tecnologia como a termografia infravermelha, são eficazes para monitorar e representar a temperatura corporal de forma passiva e sem ter contato físico com o animal (Zanghi, 2016). Entre 29 e $34^{\circ} \mathrm{C}$, encontra-se a zona termoneutra para murinos (David et al., 2013). Ratos e camundongos controlam a temperatura corporal central, principalmente, pela vasorregulação da cauda. No entanto, a área da superfície da cabeça é também um conhecido dissipador de calor, pela convecção de calor e evaporação de lágrimas que permitem a transmissão do calor do crânio para a superfície do globo ocular (Eguibar et al., 2017). Uma vez que os olhos são irrigados pela artéria oftálmica do cérebro, a temperatura da superfície ocular pode ser uma abordagem não invasiva para medir a temperatura do eixo cérebro-coração ou da temperatura retal, que estão relacionadas com a temperatura corporal (Vogel et al., 2016). Observa-se, no presente estudo, que a ação do ômega 3 e da vitamina B12, isolados ou associados, não influenciou de forma significativa na temperatura do globo ocular e, provavelmente, não alterou a temperatura corpórea.

Um elemento significativo observado na pesquisa é o aumento da temperatura do escroto no grupo vitamina B12, em relação aos demais grupos. A exposição do escroto ao calor pode acarretar alterações morfológicas nos testículos e inibir a espermatogênese em mamíferos, incluindo seres humanos, ratos, macacos touros e ovelhas. $\mathrm{O}$ aquecimento testicular tem sido associado a um aumento no estresse oxidativo e sua avaliação pode desencadear a compreensão da patogênese em muitas doenças (Calkosinski et 
al., 2015). Como resultado da produção excessiva de ROS, os espermatozoides podem sofrer danos no DNA mitocondrial e no nuclear, juntamente com lesão peroxidativa da membrana plasmática, o que pode levar à supressão da espermatogênese e afetar a fragmentação do DNA. A integridade do DNA afeta a competência funcional do gameta (Cissen et al., 2016). O ômega 3 pode desempenhar o papel antioxidante e diminuir fatores inflamatórios (Kemse et al., 2014). A suplementação com vitamina B12 diminui o teor de ROS produzido pelo estresse oxidativo no sêmen (Hamedani et al., 2013).

Nas imagens de prepúcio e focinho, houve diferenças entre os tratamentos, mas os resultados podem sofrer influências que não foram controladas no presente estudo. Ao se realizarem as imagens termográficas, resíduos de urina do próprio animal podem umedecer a região e alterar a leitura da temperatura do prepúcio, corroborando resultados previamente relatados (Calkosinski et al., 2015).

A eficiência reprodutiva é influenciada pela nutrição, pelo estado nutricional (Punab et al., 2017) e pelo peso dos órgãos reprodutivos; este é um parâmetro que pode indicar alterações nas concentrações de hormônios sexuais (Fernandes et al., 2012). No presente estudo, os tratamentos não alteraram $\mathrm{o}$ peso dos testículos, dos epidídimos e da vesícula seminal.

Quanto aos aspectos histomorfológicos de testículo, o ômega 3 provocou alterações no epitélio e no estroma. A presença do ômega 3, na dose utilizada, pode ter provocado um desequilíbrio entre antioxidantes e teores de ROS. A membrana plasmática do espermatozoide é rica em ácidos graxos poliinsaturados, o ácido docosa-hexaenoico (DHA), que possui seis duplas ligações por molécula, tornando-o vulnerável ao estresse oxidativo e a outras modificações químicas e estruturais. Os ROS atacam bases de DNA e os esqueletos fosfodiéster, provocando desestabilização celular, o que resulta em fragmentação do DNA (Gharagozloo e Aitken, 2011).

Quando associados ômega 3 e vitamina B12, observa-se que o efeito deletério do ômega 3 é mitigado, demonstrado na porcentagem de epitélio seminífero e na porcentagem de estroma, não diferindo estatisticamente do grupo controle. A suplementação com vitamina B12 auxilia na replicação celular, especialmente na síntese de DNA e RNA (Almeida, 2014), pode prevenir peroxidação lipídica e ter ação antioxidante, combatendo ROS (Hamedani et al., 2013) e minimizando seus efeitos tóxicos na espermatogênese. A toxicidade nos espermatozoides pode ocorrer, mesmo sem alterações histopatológicas, e ser detectável na análise direta do espermatozoide (De Grava e Klinefelter, 2014).

Ao se avaliar a morfologia espermática, os ratos que receberam apenas a vitamina B12 apresentaram maior porcentagem de espermatozoides normais e menor porcentagem de espermatozoides com patologias de cabeça, comparados aos demais grupos. Estudos confirmam que a deficiência de vitamina B12 aumenta o número de espermatozoides anormais e a adequação na ingestão auxilia na espermatogênese (Almeida, 2014).

Danos induzidos por ROS resultam em defeitos espermáticos, como cabeça anormal, defeitos de acrossomo, gota citoplasmática e defeitos de cauda. Entre diferentes anomalias espermáticas, o citoplasma residual ou a gota citoplasmática podem ser considerados como os mais importantes na produção de ROS (Sabeti et al., 2016).

No grupo vitamina B12, houve elevação da porcentagem de gota distal. A presença de gota citoplasmática está relacionada com a interrupção ou a cessação da espermiogênese ou da maturação epididimária (Rengan et al., 2012), em razão de não se terem fechado os ciclos do epitélio seminífero. Em ratos Wistar, a duração da espermatogênese completa requer entre 4,0 e 4,5 ciclos do epitélio seminífero (Russel et al., 1990), com duração de 13 dias cada (Huckins, 1965), totalizando aproximadamente 52 dias. O sacrifício dos animais ocorreu aos 30 dias do experimento, o que pode ter influenciado na maturação espermática do grupo vitamina B12, que se presume ter aumentado a produção de espermatozoides. No epidídimo, acontece o processo de maturação espermática, e a aceleração do trânsito do espermatozoide pelo epidídimo reduz o tempo disponível para os processos necessários para a maturação, o que pode comprometer a sua função (De Grava e 
Klinefelter, 2014). Durante o trânsito epididimário, na maioria dos espermatozoides, a gota protoplasmática migra ao longo da cauda do espermatozoide e é eliminada na ejaculação (Rengan et al., 2012). A retenção das gotas nos espermatozoides ejaculados tem sido associada à infertilidade (García-Vásquez et al., 2015).

No presente estudo, o aumento da porcentagem de gota distal está altamente correlacionado, de forma positiva, com a elevação da temperatura do escroto. A hipertermia escrotal eleva o estresse oxidativo e a apoptose de células germinativas (Lin et al. 2016). Porém, um equilíbrio entre a produção de ROS e antioxidantes não provocará estresse oxidativo e prejuízos na fertilização. A terapia antioxidante pode resultar em espermatogênese normal e não afetar a fertilidade (Sabeti et al., 2016).

\section{CONCLUSÕES}

A termografia infravermelha é um método alternativo para estudo de efeitos do ômega 3 e da vitamina B12 nas temperaturas do escroto e em áreas do corpo de ratos. A elevação da temperatura do escroto resulta no aumento da porcentagem de gotas citoplasmáticas distais. A temperatura do globo ocular não sofre influência significativa do ômega 3 e da vitamina B12. O ômega 3 reduz o epitélio seminífero, e a vitamina B12 minimiza esse efeito.

\section{AGRADECIMENTO}

Ao Conselho Nacional de Desenvolvimento Científico e Tecnológico (CNPq) pelo fomento concedido e pela bolsa de produtividade em pesquisa (Processo 306964/2014-7).

\section{REFERÊNCIAS}

ADAMKOVICOVA, M.; TOMAN, R.; CABAJ M. et al. Effects of subchronic exposure to cadmium and diazinon on testis and epididymis in rats. Sci. World J., v.2014, [9p.], 2014.

ALMEIDA, T.B. Avaliação de parâmetros morfométricos e morfofuncionais em testículos de ratos tratados com fluoxetina e suplementados com vitamina B12. 2014. 55f. Monografia (Trabalho de Conclusão de Curso) - Universidade Estadual Paulista, Araraquara, SP.
CAŁKOSIŃSKI, I.; DOBRZYNSKI, M.; ROSINCZUK, J. et al. The use of infrared thermography as a rapid, quantitative, and noninvasive method for evaluation of inflammation response in different anatomical regions of rats. BioMed. Res. Int., v.2015, [9p.], 2015.

CISSEN, M.; WELY, M.V.; SCHOLTEN, I. et al. Measuring sperm DNA fragmentation and clinical outcomes of medically assisted reproduction: a systematic review and meta-analysis. PLOS ONE, v.11, p.e0165125, 2016.

DAVID, J.M.; CHATZIIOANNOU, A.F.; TASCHEREAU, R. et al. The hidden cost of housing practices: using noninvasive imaging to quantify the metabolic demands of chronic cold stress of laboratory mice. Comp. Med. v.63, p.386-391, 2013.

DE GRAVA, K.W.; KLINEFELTER, G.R. Interpreting histopathology in the epididymis. $J$. Spermatogenesis, v.4, n.2, 2014

EGUIBAR, J.R.; URIBE, C.A.; CORTES, C. et al. Yawning reduces facial temperature in the highyawning subline of Sprague-Dawley rats. BMC Neurosci., v.18, n.3, 2017.

FERNANDES, G.S.; ARENA, A.C.; CAMPOS, K.E. et al. Glutamate-induced obesity leads to decreased sperm reserves and acceleration of transit time in the epididymis of adult male rats. Reprod. Biol. Endocrinol., v.10, n.105, 2012.

FILLER, R. Methods for evaluation of rats epididymal sperm morphology. In: CHAPIN, J.H.H. (Ed.). Male reproductive toxicology. California: Academic Press, 1993. p.334-343.

GARCÍA-VÁZQUEZ, F.A.; HERNANDEZCARAVACA, I.; MATÁS, C. et al. Morphological study of boar sperm during their passage through the female genital tract. J. Reprod. Develop., v.61, p.407413,2015

GHARAGOZLOO, P.; AITKEN, R.J. The role of sperm oxidative stress in male infertility and the significance of oral antioxidant therapy. Hum. Reprod., v.26, p.1628-1640, 2011.

GIAHI, L.; MOHAMMADMORADI, S.; JAVIDAN, A. et al. Nutritional modifications in male infertility: a systematic review covering 2 decades. Nutr. Rev., v.74, p.118-130, 2016.

GRISWOLD, M.D. Spermatogenesis: the commitment to meiosis. Physiol. Rev., v.96, p.1-17, 2016.

HAMEDANI, M.A.; TAHMASBI, A.M.; AHANGARI, Y.J. Effects of vitamin $B_{12}$ supplementation on the quality of ovine spermatozoa. Open Vet. J., v.3, p.140-144, 2013. 
HANNIBAL, L.; LYSNE, V.; BJØRKE-MONSEN, A.L. et al. Biomarkers and algorithms for the diagnosis of vitamin $\mathrm{B}_{12}$ deficiency. Front. Molec. Biosci., v.3, n.27, 2016.

HIRABARA, S.M.; FOLADOR, A.; FIAMONCINI, J. et al. Fish oil supplementation for two generations increases insulin sensitivity in rats. J. Nutr. Biochem., v.24, p.1136-1145, 2012.

HUCKINS, C. Duration of spermatogenesis in pre and post puberal Wistar rat. Anat. Rec., v.151, n.364, 1965.

KEMSE, N.G.; KALE, A.A.; JOSHI, S.R. A combined supplementation of Omega-3 fatty acids and micronutrients (Folic Acid, Vitamin $\mathrm{B}_{12}$ ) reduces oxidative stress markers in a rat model of pregnancy induced hypertension. PLos One, v.9, p.e111902, 2014.

LIN, C.; CHOI, Y.S.; PARK, S.G. et al. Enhanced protective effects of combined treatment with $\beta$ carotene and curcumin against hyperthermic spermatogenic disorders in mice. BioMed. Res. Int. v.2016, 2016

MENDELUK G.R.; COHEN, M.I.; FERRERI, C.; CHATGILIALOGLU, C. Nutrition and reproductive health: sperm versus erythrocyte lipidomic profile and $\omega$-3 intake. J. Nutr. Metabol., v.2015, 8p., 2015.

MINITAB 16 software estatístico [software informático]. Belo Horizonte: Minitab, 2010.

OLIVEIRA, B. Vitamina B12 exerce um efeito benéfico sobre a espermatogênese após depleção de espermatogônias causada pelo Busulfan ${ }^{\circledR}$. 2013. 50f. Monografia (Graduação em Ciências Farmacêuticas) Universidade Estadual Paulista, Araraquara, SP.
PUNAB, M.; POOLAMETS, O.; PAJU P. et al. Causes of male infertility: a 9-year prospective monocentre study on 1737 patients with reduced total sperm counts. Hum. Reprod., v.32, p.18-31, 2017.

RENGAN, A.K.; AGARWAL, A.; VAN DER LINDE, M.; PLESSIS, S.S. An investigation of excess residual cytoplasm in human spermatozoa and its distinction from the cytoplasmic droplet. Reprod. Biol. Endocrinol., v.10, n.92, 2012.

RISSO, A.; PELLEGRINO, F.J.; RELLING, A.E.; CORRADA, Y. Effect of long-term fish oil supplementation on semen quality and serum testosterone concentrations in male dogs. Int. J. Fertil. Steril., v.10, p.223-231, 2016.

RUSSEL， L.D.; ETTLIN, R.A.; HIKIN, A.P.S.; CLEGG, E.D. The classification and timing of spermatogenesis. In: — Histological and histopathological evaluation of the testis. Clearwater: Cache River Press, 1990. p.41-58.

SABETI, P.; POURMASUMI, S.; RAHIMINIA, T. et al. Etiologies of sperm oxidative stress. Int. J. Reprod. Biomed., v.14, p.231-240, 2016.

USAMENTIAGA, R.; VENEGAS, P.; GUEREDIAGA, J. et al. Infrared thermography for temperature measurement and non-destructive testing. Sensors, v.14, p.12305-12348, 2014.

VOGEL, B.; WAGNER, H.; GMOSER, J. et al. Touch-free measurement of body temperature using close-up thermography of the ocular surface. MethodsX, v.3, p.407-416, 2016.

ZANGHI, B.M. Eye and ear temperature using infrared thermography are related to rectal temperature in dogs at rest or with exercise. Front. Vet. Sci., v.3, n.111, 2016. 